\title{
AN UNUSUAL FOREIGN BODY IN HUMAN OESOPHAGUS - CASE REPORT
}

\author{
${ }^{*}$ A.L. Okhakhu, *F.O. Ogisi \\ *ENT Unit, Department of Surgery, University of Benin Teaching Hospital, \\ Benin City.
}

\section{ABSTRACT}

We report a case of a 65year old Nigerian male with an unusual foreign body, a fishing hook in the oesophagus. This was confirmed with a plain radiograph of the chest done on a routine medical check-up, although patient was asymptomatic. The foreign body was removed via a rigid oesphagoscopy without any complication. The need for appropriate and prompt management of oesophageal foreign bodies is emphasized.

Key word: Foreign body, fish hook, oesophagus, human.

\section{INTRODUCTION}

Foreign bodies of the aerodigestive tract have been reported to be a common otolaryngological emergency at the extremes of life. Children who are less than five years of age are particularly vulnerable because of their inquisitive nature and the tendency to explore every available cavity in their body ${ }^{1-5}$. Various objects are ingested; ranging from coins, plastics, pebbles, parts of toys and corrosive agents. Objects commonly ingested by young adults and the elderly may be accidental or deliberate and include corrosives especially in those suffering from psychiatric illnesses and dentures. Fatal complications have been reported in cases of impacted oesophageal foreign bodies due to late diagnosis, late referral to hospital and mismanagement ${ }^{6-7}$.

We report a case of a fishing hook in the oesophagus in an elderly man. A search through the literature revealed only a single documented similar case of a fishing hook in the hypopharynx ${ }^{8}$. Fish hook in oesophagus of animals is well documented $^{9}$.

\section{CASE REPORT}

A case of a 65 years old male trader who presented to the ENT Unit of University of Benin Teaching Hospital Benin-city as a case of referral from a private hospital on account of a radioopaque foreign body detected on a routine chest radiograph. He was asymptomatic but on further probing he volunteered a history of transient self limiting chest pain following a meal about three month before presentation. This was not associated with vomiting, cough, dysphagia, dyspnoea or feverish feelings.

Physical examination was unremarkable. However, a repeat soft tissue neck and chest radiograph revealed a curved radio-opaque object in the prevertebral soft tissue at the level of $\mathrm{T}_{2} / \mathrm{T}_{3}$ (fig 1). Results of haematological and biochemical investigations were within normal limits. Based on these, a diagnosis of foreign body in the oesophagus (fishing hook) was made.

The patient was worked up for rigid oesophagoscopy and foreign body removal under general anaesthesia. Intraoperative findings were that of a rusted metal fishing hook adherent to the proximal part of the oesophagus measuring $26 \mathrm{~mm}$ which was retrieved at about $22 \mathrm{~cm}$ level and was delivered along with the oesophagoscope using a grasping forceps (Fig 2). A naso-gastric tube was passed. Post operatively patient was placed on nil by mouth and intravenous antibiotics for 48 hours while vital signs were monitored. Thereafter, he was placed on graded oral intake which was well tolerated and

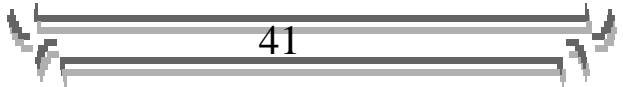


was subsequently discharged home to be followed up in the clinic.

\section{PICTURES}

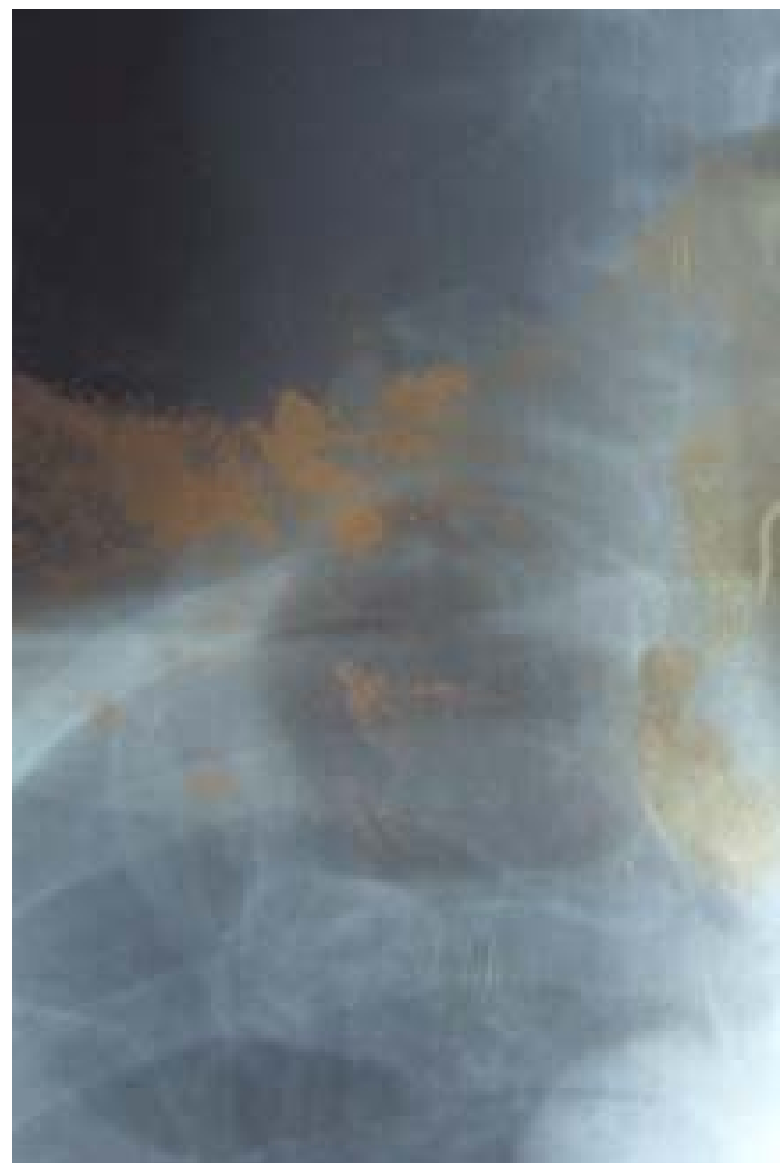

Fig. 1: X-ray showing the fish hook.

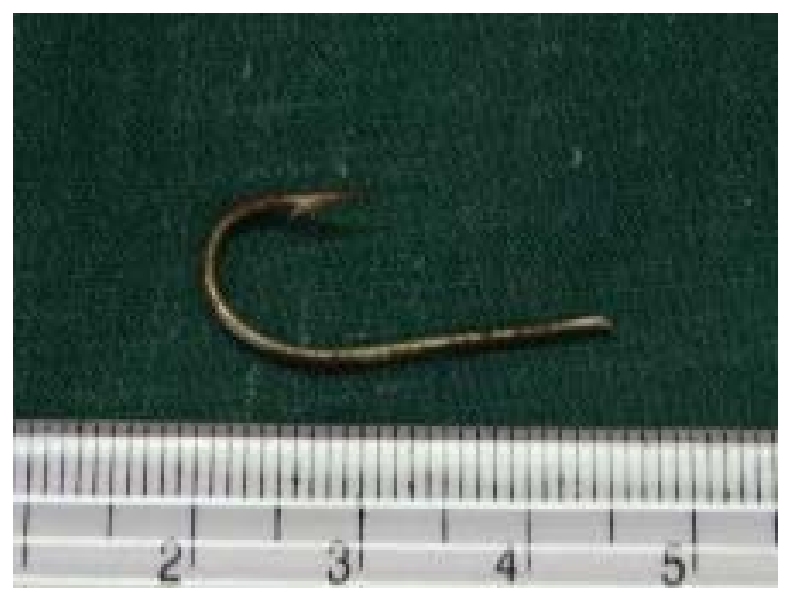

Fig. 2: The extracted fish hook.

\section{DISCUSSION}

Foreign bodies in the aero-digestive constitute a common otorhinolaryngological problem especially in the extremes of life. It presents commonly with chest pain, drooling, dysphagia, odynophagia and vomiting depending on its location. Angulated foreign bodies tend to be trapped in the proximal oesophagus ${ }^{14}$. Penetrating or sharp foreign bodies are more dangerous as they tend to get buried in the mucosa of the oesophagus or perforate it with disastrous consequences ${ }^{10}$. Migration of sharp oesophageal foreign bodies may result in serious complications such as oesophageal perforation, mediastinitis, lung abscess, peritonitis, ${ }^{6,10}$. Stricture formation with resultant regurgitation are known complications which may result from oesophageal foreign body ingestion or its management ${ }^{10,11}$.

Hard or sharp foreign objects in food may cause traumatic injury such as laceration of the soft tissues of the oral cavity, throat, stomach and intestine. From 1972 through 1997, the FDA Health Hazard Evaluation Board evaluated approximately 190 cases of hard or sharp foreign objects in food. These include cases of both injury and non-injury reported to FDA. The Board found that foreign objects that are less than $7 \mathrm{~mm}$, maximum dimension, rarely cause trauma or serious injury except in special risk groups such as infants, surgery patients, and the elderly. This emphasizes the need for careful preparation of food and the need for proper mastication before swallowing. In the index case, the fishing hook was swallowed undetected. This is a common finding in the elderly with loss of palatal tactile sensation occasioned by prolonged use of upper dentures ${ }^{12}$.

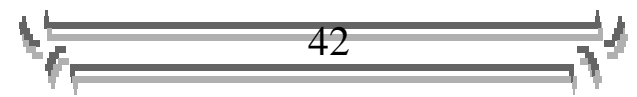


This was however not the case with this patient as he did not have a denture.

Early diagnosis of oesophageal foreign bodies may occur if the object is radio-opaque. Delays may occur in cases of non-opaque materials such as dentures ${ }^{13}$.

The removal of the foreign body was necessary to forestall possible complications such as migration, perforations of the oesophagus with subsequent mediastinitis ${ }^{10}$. Removal of oesophageal foreign bodies by the unskilled in endoscopic retrieval is associated with laceration of the mucosal lining of the oesophagus. This can be minimized by ensuring removal is undertaken by skilled health personnel who is more likely to withdraw the grasped foreign body together with the endoscope, as done in this case.

\section{CONCLUSION}

There is need for proper preparation of all food before consumption and the need to masticate food properly before swallowing. Oesophageal foreign bodies should be managed promptly and appropriately.

\section{REFERENCE}

1. Wilson JA. The oesophagus. In: Kerr AG, Hibbert J (eds). Otolaryngology. Scott-Brown's Otolaryngology. Laryngology and head and neck surgery. Butterworth-Heinemann, Oxford, 1997; 5/24/21-5/24/22.

2. Bressler $\mathrm{K}$, Shelton $\mathrm{C}$, Ear foreign body removal; a reviewing of 98 consecutive cases. Laryngoscope 1993; 103: 367-70.

3. Kumar S. Management of foreign bodies in the ear, nose and throat. Emerg. Med. Australia 2004 Feb; 16(1): 17-20.
4. Hon. SK, Izam TM, Koay CB, Razi A.: A prospective evaluation of foreign bodies. Presenting to the ear nose and throat clinic hospital Kuala Lumpur. Med. J. Malaysia 2001 Dec; 56(4): 463-70.

5. Okafor BC. Foreign bodies in the pharynx and oesophagus. Nigerian Medical Journal 1979; 9: 321-325.

6. Okafor BC. Lung abscess secondary to oesophageal foreign body. Ann Otol Rhinol Laryngol 1978;87: 568570.

7. Obiako MN. Tracheoesophageal fistula. A complication of foreign body. Ann Otol Rhinol Laryngol 1982;91: 325-329.

8. Swanson PB, Apicella SA, Rosen CA. Removal of a triple-barbed fishhook from the hypopharynx with microlaryngoscopy, Am. J otolarygol head and neck, 2002; 23:233 -236.

9. Hyland RJ. Surgical removal of a fish hook from the oesophagus of a turtle Aust Vet J 2002; 80: 54-56.

10. Badoe EA, Archampong EQ, da Rocha-Afodu JT: Foreign bodies in the oesophagus in principles and practice of surgery including Surgical pathology in the tropics $3^{\text {ro }}$ edition Ghana Pub. Cop. 2000; 356357.

11. Elusoji SO, Ogundiran O, Mafeni J. Management of impacted denture in the oesophagus. Nig. J of Med. 1987(3):120-121.

12. Dhingra PL. Foreign bodies of food passage in diseases of Ear, Nose and Throat third edition Elsevier 2004; 406-408.

13. McCanse DE, Kurchin A, Hinshaw R. Gastrointestinal foreign bodies. Am J Surg 1981; 142: 335 - 337.

14. Taylor RB. Esophageal foreign bodies. Emerg Med Clin North Am 1987; 5: 301-11.

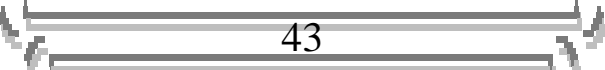

